\title{
A STUDY OF THE HYDROGEN-ANTIMONY-TIN METHOD FOR THE DETERMINATION OF OXYGEN IN CAST IRONS
}

\author{
By Bengt Kjerrman and Louis Jordan
}

\begin{abstract}
A comparison of the vacuum fusion and the hydrogen-antimony-tin reduction methods for the determination of oxygen in cast-iron samples indicated that it is very important that lump samples rather than milled samples be used in either method in order to avoid erroneous results for oxygen due chiefly to the adsorption of air and moisture on milled samples and, in a lesser degree, to surface oxidation.

Within the precision of the method-namely, about 0.006 per cent oxygenthe hydrogen reduction procedure gave the same values for oxygen in cast-iron samples as the vacuum-fusion method. The precision of the latter method, however, was of the order of 0.001 per cent oxygen. For application to cast irons containing oxygen within the range of the samples used-namely, from 0.01 to 0.04 per cent-the vacuum-fusion method is to be preferred on the basis of its greater precision.

The complexity of the "blank" corrections necessary in the application of the hydrogen reduction method to high-carbon iron alloys is pointed out and discussed.

The limitation of the hydrogen-antimony-tin method to low silicon materials, said to be necessary in the case of low-carbon iron alloys, appears not to hold in the case of high carbon alloys where the carbon plays a greater part than the hydrogen in the reduction of the oxides in the sample.
\end{abstract}

\section{CONTENTS}

I. Introduction

II. Cast-iron samples

III. Oxygen content of cast irons by the vacuum-fusion method

1. Lump samples

2. Milled samples_._.

IV. Oxygen content of cast irons by the hydrogen-antimony-tin method.--

1. Apparatus... Antimony-tin al

2. Antimony-tin alloy

3. Detailed procedure

4. Blanks _.

5. Application of method to cast-iron samples

VI. Conclusions 


\section{INTRODUCTION}

The investigation described in the present report was undertaken in 1925 as a portion of the work on gases in metals which was carried out at the Bureau of Standards under a research fellowship of the Swedish Engineers' Academy of Science (Ingeniors Vetenskaps Akademien). The object of the research was to study the application to cast irons of the "hydrogen-antimony-tin" method ${ }^{1}$ for the determination of oxygen and to compare the results given by this method. with those given by the vacuum-fusion method generally used in the bureau's laboratories.

Oberhoffer ${ }^{2}$ has briefly and clearly traced the evolution of the hydrogen-antimony-tin method from the original Ledebur method. Following the early modifications of the original Ledebur procedure, which were attempts to increase the accuracy and decrease the time required for the determination, it was shown that by changing the temperature of the reduction from $950^{\circ} \mathrm{C}$. to above $1,200^{\circ} \mathrm{C}$. the amount of oxygen found in a given steel was increased. This increase in operating temperature, however, introduced new difficulties and led to the addition of antimony and tin to the steel sample in order to lower the melting point to a range in which readily available refractory tubes and furnaces were serviceable. It appeared that the reduction of manganous oxide was aided by the addition of antimony and tin, and that a partial reduction of ferrous silicates was also secured.

However, further study of the method showed that the presence of carbon in the sample caused an error, in that a very considerable reduction of the oxides in the sample by this carbon took place, with the evolution of large proportions of the oxygen as carbon dioxide and carbon monoxide, gases which were not determined in the regular procedure. Thereupon the method was modified ${ }^{3}$ to provide for the recovery of carbon dioxide and carbon monoxide in addition to water vapor. The conclusions were, however, that the modified method was very complicated, and that the simple hydrogen-reduction method (in which there is the addition of an alloying metal or metals and the recovery only of water vapor) was best retained, with the understanding that it was applicable only to samples low in carbon and not containing any considerable amounts of difficulty reducible oxides, such as silica and alumina.

\footnotetext{
$1 \mathrm{~J}$. Keutman and P. Oberhoffer, "II. Bestimmung des Sauerstoffs nach dem Wasserstoffverfahren unter Zuschlag von Zinn-Antimon-Legierung," Stahl und Eisen, 45, pp. 1557-1559; 1925.

2 P. Oberhofier, "Sauerstoff im Eisen," Stahl und Eisen, 45, pp. 1379-1384; 1925.

3 P. Oberhoffer, E. Piwowarsky, A. Pfeifer-Schiessl and H. Stein, "Ueber Gas und Sauerstoffbestim. mungen im Eisen, Insbosondere Gusseisen," Stahl und Eisen, 44, pp. 113-116; 1924.
} 
Very recently, and since the completion of the experimental work to be described in this report, Thanheiser and Müller ${ }^{4}$ and Bardenheuer and Müller ${ }^{5}$ have published two papers dealing with the limitations of the hydrogen reduction method. Thanheiser and Müller stated that the hydrogen-reduction method, using antimony alone as the alloying addition, is further limited to low-carbon irons containing little or no silicon. This, they indicate, is because during the determination, ferrous and manganous oxides are in large part reduced by the silicon in the steel with the formation of silica. The oxygen thus combined with silicon escapes determination. Even with as little as 0.05 per cent silicon in a steel containing 0.02 per cent carbon, less than 50 per cent of the 0.03 per cent oxygen present in the sample was found by the hydrogen reduction method. Bardenheuer and Müller add to these limitations the requirement of a low phosphorus content.

Oberhoffer and his collaborators ${ }^{6}$ have considered that the modification of the hydrogen-antimony-tin method, which provides for the recovery of carbon dioxide and carbon monoxide, yields accurate results for oxygen in high-carbon alloys. On account, however, of the complicated train and procedure required in this method, they state that it is best to resort to a vacuum-fusion method for determining oxygen in a high-carbon iron alloy.

In the present work it was desired to study critically the hydrogenantimony-tin method as applied to a high-carbon iron alloy, specifically cast irons, with suitable provision for recovering carbon dioxide and carbon monoxide in addition to the water vapor, and to compare such a procedure with the graphite-crucible vacuum-fusion determination of oxygen as applied to the same iron samples.

\section{CAST-IRON SAMPLES}

The material upon which the analyses were made was a pig iron of the following composition as represented by a single vertical crosssection slice (slice No. 3):

Per cent

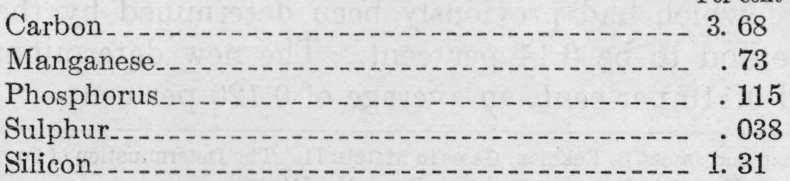

All samples were taken from a single pig, designated as No. 4, which was cut into a number of vertical cross section slices, each

${ }^{4}$ G. Thanheiser and C. A. Müller, "Der Einfluss des Siliziums auf die Sauerstoftbestimmung im Wasserstofistrom," Mitt. Kaiser-Wilhelm Inst. Eisenforsch. Düsseldorf, 9, pp. 211-213; 1927.

s P. Bardenheuer and C. A. Müller, "Einfluss einiger Begleitelemente des Eisens auf die Sauerstoffbestimmung im Stahl nach dem Wasserstoffreduktionsverfahren," Archiv. Eisenhüttenwesen 1, pp. 707-709; 1928.

6 See footnote 3. 
about $10 \mathrm{~mm}$ thick. These slices were numbered consecutively from one end of the pig. Thus, " $4-3$ " indicates the third slice of the No. 4 pig. The location of the samples in the cross-section slice was designated by the letters $a, b$, and $c$, as shown in Figure 1 .

At the conclusion of the work analyses were also made on a special cast iron containing high manganese and silicon.

\section{OXYGEN CONTENT OF CAST IRONS BY THE VACUUM- FUSION METHOD}

The vacuum-fusion method for oxygen, as described by Jordan and Eckman ${ }^{7}$ was employed for determining the total oxygen content of the pig iron. The results obtained by Jordan and Eckman in their development of this method indicate that it should yield the oxygen present in a ferrous alloy, including that combined as silica or as manganous oxide. Further, the presence of large amounts of carbon in the iron sample is an essential factor of the vacuum-fusion method and should be expected to cause no interference, as in the case of the hydrogen-antimony-tin method. The vacuum-fusion method should, therefore, be suitable for the determination of oxygen in cast-iron samples. ${ }^{8}$ The blanks determined for the vacuum-fusion analyses are given in Table 1 .

\section{TABLE 1.-Blanks for vacuum-fusion method}

\begin{tabular}{|c|c|c|}
\hline Test No. & $\begin{array}{c}\text { Oxygen } \\
\text { blank }\end{array}$ & $\begin{array}{c}\text { Hydrogen } \\
\text { blank }\end{array}$ \\
\hline $\begin{array}{l}1 \\
1 \\
2 \\
3 \\
4\end{array}$ & $\begin{array}{c}g \\
0.0048 \\
.0044 \\
.0052 \\
.0046\end{array}$ & $\begin{array}{c}g \\
0.00050 \\
.00044 \\
.00041 \\
.00034\end{array}$ \\
\hline A verage & .0048 & .00042 \\
\hline
\end{tabular}

In order to test the performance of the entire apparatus before starting the analyses of the pig-iron sample, duplicate determinations were made on a pure iron ingot, made from electroly tic iron, the oxygen content of which had previously been determined by the vacuumfusion method to be 0.14 per cent. The new determinations gave 0.124 and 0.116 per cent, an average of 0.120 per cent.

\footnotetext{
${ }^{7}$ Louis Jordan and James R. Eckman, Gases in Metals: II. The Determination of Oxygen and Hydrogen in Metals by Fusion in Vacuum, B. S. Sci. Paper No. 514; 1925.

8 Recent results obtained in the course of the modification and improvement of the vacuum-fusion method have indicated that the gases delivered to the gas analysis train from the fusion of ferrous materials containing free manganese may not be a true measure of the total oxygen content of the sample.
} 


\section{LUMP SAMPLES}

The analyses of lump samples of pig iron No. 4 were then made, with the results given in Table 2 .

TABLE 2.-Oxygen in pig iron No. 4 by vacuum-fusion analysis of lump sample

\begin{tabular}{|c|c|c|c|c|c|c|c|}
\hline \multirow[b]{2}{*}{ Pig-iron sample No. } & \multirow{2}{*}{$\begin{array}{l}\text { Weight } \\
\text { of } \\
\text { sample }\end{array}$} & \multirow{2}{*}{$\begin{array}{c}\text { Total } \\
\text { oxygen } \\
\text { found }\end{array}$} & \multirow{2}{*}{$\begin{array}{c}\text { Total } \\
\text { hydrogen } \\
\text { found }\end{array}$} & \multicolumn{2}{|c|}{ Blank corrections } & \multicolumn{2}{|c|}{ Corrected values } \\
\hline & & & & Oxygen & $\begin{array}{c}\text { Hydro- } \\
\text { gen }\end{array}$ & Oxygen & $\begin{array}{c}\text { Hydro- } \\
\text { gen }\end{array}$ \\
\hline $\begin{array}{l}4-a-2 \\
4-a-2 \\
4-a-3 \\
4-a-3 \\
4-c-3\end{array}$ & $\begin{array}{c}g \\
28.24 \\
32.86 \\
38.75 \\
31.90 \\
35.04\end{array}$ & $\begin{array}{l}g \\
0.0066 \\
.0074 \\
.0074 \\
.0078 \\
.0039\end{array}$ & $\begin{array}{c}g \\
0.00038 \\
.00047 \\
.00049 \\
.00051 \\
.00030\end{array}$ & $\begin{array}{r}g \\
0.0048 \\
.0048 \\
.0048 \\
.0048 \\
1.0017\end{array}$ & $\begin{array}{c}g \\
0.00042 \\
.00042 \\
.00042 \\
.00042 \\
1.0002\end{array}$ & $\begin{array}{r}\text { Per cent } \\
0.006 \\
.008 \\
.007 \\
.009 \\
.006\end{array}$ & $\begin{array}{r}\text { Per cent } \\
0.0002 \\
.0002 \\
.0003 \\
.0002\end{array}$ \\
\hline $\begin{array}{l}4-c-3-3 \\
4-c-3 \\
4-c-3 \\
4-b-3 \\
4-b-3\end{array}$ & $\begin{array}{l}30.76 \\
30.17 \\
25.85 \\
41.77 \\
41.15\end{array}$ & $\begin{array}{l}.0034 \\
.0057 \\
.0054 \\
.0048 \\
.0061\end{array}$ & $\begin{array}{l}.00025 \\
.00035 \\
.00032 \\
.00024 \\
.00035\end{array}$ & $\begin{array}{l}.0012 \\
.0010 \\
.0012 \\
.0006 \\
.0010\end{array}$ & $\begin{array}{l}.0001 \\
.0002 \\
.0002 \\
.0001 \\
.0001\end{array}$ & $\begin{array}{l}.007 \\
.015 \\
.014 \\
.010 \\
.013\end{array}$ & $\begin{array}{l}.0002 \\
.0005 \\
.0005 \\
.0003 \\
.0005\end{array}$ \\
\hline
\end{tabular}

1 The last 6 determinations listed in this table were made by an improved form of the vacuum-fusion method in which the magnitude of the blank has been materially reduced.

The analyses originally made were only those on the 4-a-2 and 4-a-3 samples. (Fig. 1.) Subsequently, additional determinations were made on four samples cut from the "c" section of the third slice of pig iron No. 4 (the 4-c-3 samples) in the position indicated by the dotted lines on section "c" in Figure 1. Unfortunately, the rela-

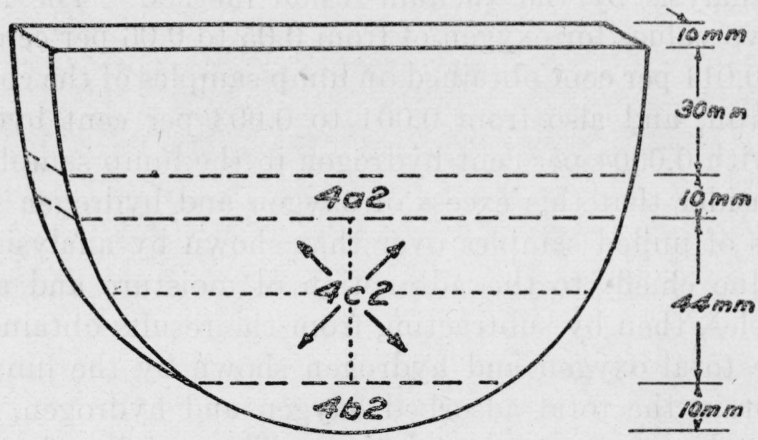

Frg. 1.-Location of analytical samples in cross section of pig iron No. 4

tive positions of these four samples were not recorded. Two of the four samples checked the oxygen result obtained on the "a" samples of slices 2 and 3, giving 0.006 and 0.007 per cent as compared with an average of 0.008 for the four "a" samples. The other two samples, however, were very much higher in oxygen; namely, 0.015 and 0.014 per cent. Two additional analyses made on samples from the "b" section of slice 3 gave 0.010 and 0.013 per cent oxygen. It thus appears that appreciable segregation of oxygen 
occurred near the bottom of the "c" section in each cross-section slice of the pig. The milled sample of this pig iron, which was subsequently used in analyses both by vacuum-fusion and by hydrogenreduction methods, was the entire "c" section of slice 2 . The true oxygen content of this section is then to be considered as the average of the vaccuum-fusion analyses of the four 4-c-3 samples of Table 2, namely, 0.011 per cent oxygen and 0.0004 per cent hydrogen.

\section{MILLED SAMPLES}

It has apparently been the usual procedure to use a milled sample in those methods for determining oxygen in iron and steel which are dependent on reduction by hydrogen. Eckman, Jordan, and Jominy 9 have pointed out that the use of a finely divided form of a cast-iron sample leads to very large errors in determining oxygen by the vacuumfusion method. Presumably such errors are due to surface oxidation of the chips or to adsorption of moisture or of air. Oberhoffer and Keutmann ${ }^{10}$ have also found differences of from 0.02 to 0.03 per cent oxygen between lump and milled samples in analyses by the hydrogenreduction method.

The 4-c-2 sample of pig iron No. 4 was cut on a milling machine at a very slow speed and also with extreme care to prevent any contact of oil with the milled sample. The millings were not washed in any way. Portions of this 4-c-2 sample, after thorough mixing, were taken for analysis by the vacuum-fusion method. The first three analyses gave values for oxygen of from 0.05 to 0.06 per cent as compared with 0.011 per cent obtained on lump samples of the corresponding 4-c-3 iron, and also from 0.001 to 0.003 per cent hydrogen as compared with 0.0004 per cent hydrogen in the lump samples.

If we consider that this excess of oxygen and hydrogen shown by the analysis of milled samples over that shown by analysis of lump samples is due chiefly to the adsorption of moisture and air on the milled samples, then by subtracting from the results obtained on the millings the total oxygen and hydrogen shown by the lump sample we shall obtain the total adsorbed oxygen and hydrogen, including also oxygen due to surface oxidation. The weight of this excess oxygen should be at least eight times that of the adsorbed hydrogen (since the increase in hydrogen must be due to adsorbed water) and any oxygen in excess of the hydrogen equivalent should represent adsorbed air and surface oxidation. Such calculations are given below in Table 3 for eight analyses on the milled sample and taking 0.011 per cent oxygen and 0.0004 per cent hydrogen as the true values for those gases in the 4-c-2 pig-iron sample.

' J. R. Eckman, Louis Jordan, and W. E. Jominy, "The oxygen content of coke and charcoal cast irons," Trans. Am. Foundrymen's Assoc. 33 p. 431; 1926.

${ }^{10}$ P. Oberhoffer and J. Keutmann, "Zur Bestimmung des Sauerstoff im Eisen; Wasserstoffverfahren," Stahl und Eisen, 46, pp. 1045-1046; 1926. 
TABLE 3.-Adsorbed oxygen in milled sample of pig iron No. 4-c-2

\begin{tabular}{|c|c|c|c|c|c|}
\hline \multirow{2}{*}{ Date of analysis } & \multirow{2}{*}{$\begin{array}{l}\text { Weight } \\
\text { of } \\
\text { sample }\end{array}$} & \multicolumn{2}{|c|}{$\begin{array}{l}\text { Total gases from } \\
\text { milled chips }\end{array}$} & \multicolumn{2}{|c|}{$\begin{array}{c}\text { Estimated adsorbed } \\
\text { oxygen }\end{array}$} \\
\hline & & Oxygen & Hydrogen & As water & As air \\
\hline $\begin{array}{l}\text { Sept. } 11 \\
\text { Sept. } 12 \\
\text { Sept. } 24 \\
\text { Sept. } 25 \\
\text { Sept. } 28 \\
\text { Dec. } 11 \\
\text { Dec. } 12\end{array}$ & $\begin{array}{c}g \\
15.83 \\
15.05 \\
15.10 \\
15.24 \\
14.94 \\
15.00 \\
10.00\end{array}$ & $\begin{array}{c}\text { Per cent } \\
0.046 \\
.060 \\
.063 \\
.080 \\
.070 \\
.091 \\
.076\end{array}$ & $\begin{array}{r}\text { Per cent } \\
0.0030 \\
.0029 \\
.0012 \\
.0029 \\
.0024 \\
.0039 \\
.0020\end{array}$ & $\begin{array}{c}\text { Per cent } \\
0.021 \\
.020 \\
.006 \\
.020 \\
.016 \\
.028 \\
.013\end{array}$ & $\begin{array}{c}\text { Per cent } \\
0.014 \\
.029 \\
.046 \\
.049 \\
.043 \\
.052 \\
.052\end{array}$ \\
\hline
\end{tabular}

The milled sample of pig iron $4-c-2$ was cut on the day preceding the first analysis listed in Table 3 . The remaining analyses followed on the dates indicated in the table.

The total oxygen obtained from the milled samples by the vacuumfusion procedure was from 0.05 to 0.09 per cent, some four to eight times the true oxygen content of the pig iron as shown by vacuumfusion analyses of lump samples. Of this amount the oxygen adsorbed as water was calculated to be from 0.02 to 0.03 per cent and that as air from 0.02 to 0.05 per cent.

Oberhoffer and E. Piwowarsky ${ }^{11}$ have also lately shown that their vacuum-fusion procedure gave an oxygen value on millings of cast iron of from two to four times that obtained with lump samples.

The true oxygen content of the lump samples of pig iron $4-c-3$ was therefore fixed by the vacuum-fusion method as 0.011 per cent. For the milled samples taken from the second slice at the corresponding position (4-c-2) the total oxygen content, including adsorbed air and moisture, was shown by the same method to be six times the true value; namely, 0.07 per cent.

\section{OXYGEN CONTENT OF CAST IRONS BY THE HYDRO- GEN-ANTIMONY-TIN METHOD}

\section{APPARATUS}

A diagram of the apparatus assembled for carrying out the hydrogen-antimony-tin reduction method is shown in Figure 2. A cylinder of hydrogen is connected to the train through stopcock $A$; $B$ is an open-end manometer for indicating the pressure of the incoming hydrogen and is also used for testing the tightness of the train; $C$ is a bubble tube and guard tube containing sulphuric acid to indicate the rate of flow of the incoming gas; $D$ is an electric resistance furnace operated at about $800^{\circ} \mathrm{C}$. to heat a silica tube filled with

11 P. Oberhoffer and E. Piwowarsky, "Ueber den Sauerstoff im Roh und Gusseisen," Stahl und Eisen, 47 , p. $521 ; 1927$. 
copper chips. This furnace was designed to convert to water vapor the traces of oxygen in the hydrogen gas. The absorption tube $E$ contains phosphorus pentoxide for absorbing water vapor formed in the catalyst furnace $D$. The three-way stopcock $F$ permits the sweeping out of the train up to the furnace $G$ with oxygen-free hydrogen before admitting the hydrogen to the furnace. The platinum wound electric resistance furnace $G$ heats the porcelain (sillimanite) tube which contains the sample boat and sample. The weighed absorption tubes $I$ and $J$ contain, respectively, phosphorus pentoxide, for the absorption of water vapor, and ascarite, which is

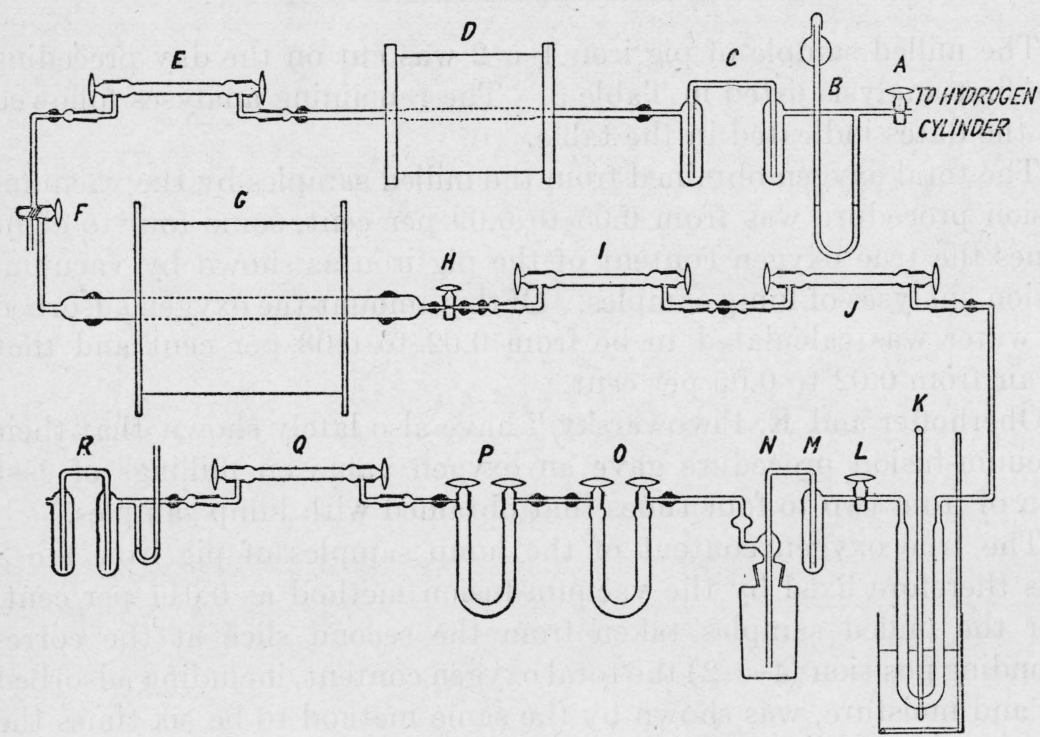

FIG. 2.-Diagram of apparatus for the determination of oxygen in cast irons by the hydrogen-antimony-tin method

guarded at each end with phosphorus pentoxide, for the absorption of carbon dioxide. The $U$-tube at $K$ contains iodine pentoxide heated in an oil bath to $150^{\circ} \mathrm{C}$. for the oxidation of carbon monoxide to carbon dioxide. The oil bath contains a thermometer and a stirring rod, as indicated. The trap $M$ is to guard against any of the solution in $N$ passing back into the tube $K$. The wash bottle $N$ contains an aqueous solution of potassium iodide ( $2 \mathrm{~g}$ of KI in $180 \mathrm{ml}$ water) for the absorption of free iodine evolved from the tube $K$ by the oxidation of carbon monoxide. Tubes $O$ and $P$ contain, respectively, sulphuric acid and phosphorus pentoxide for the preliminary and final drying of the gas which passes through the potassium iodide wash solution in $N$. The weighed absorption tube $Q$ contains ascarite and phosphorus pentoxide for the absorption of 
carbon dioxide formed by the oxidation of carbon monoxide from the sample. The open-end manometer following $Q$ and the bubble tube and guard tube $R$ indicate the pressure and the rate of flow of the hydrogen gas at the exit end of the train.

\section{ANTIMONY-TIN ALLOY}

The antimony-tin alloy used for mixing with the iron samples was prepared by melting equal weights of antimony and tin in an Acheson graphite crucible in a high-frequency induction furnace. Graphite powder was sprinkled on the surfaces of the melt. The alloy ingot was machined on the lathe to a clean cylinder of metal and then crushed in an iron mortar. The crushed alloy was cleaned with alcohol and ether, and that portion passing through a 6 -mesh but retained on a 10-mesh screen was preserved for use in a glass bottle with ground stopper, but without the use of any lubricant on the ground surfaces.

\section{DETAILED PROCEDURE}

The analyses for oxygen in the pig-iron samples by the hydrogenantimony-tin method were made generally on $5 \mathrm{~g}$ samples of the iron with $10 \mathrm{~g}$ of the antimony-tin alloy, heated at $1,200^{\circ} \mathrm{C}$. The sample, with the antimony-tin alloy, was placed in an alundum boat which had previously been heated in hydrogen. This boat and its contents were placed at the middle in the porcelain tube within furnace $G$. (Fig. 2.) The temperature of the section of the porcelain tube occupied by the boat was determined by means of a platinum, platinum-rhodium thermocouple whose hot junction was placed between the porcelain furnace tube and the outer alundum core which supported the platinum furnace winding.

It is of the utmost importance that no oxygen, either from the air or from impure hydrogen, shall at any time enter the porcelain tube of furnace $G$. In order to prevent such entrance of oxygen it is best to maintain between runs a pressure of hydrogen within the porcelain tube slightly above atmospheric pressure, or still better, to maintain, if possible, a very slow stream of hydrogen (about 15 bubbles per minute at $C$ ) through the train as far as stopcock $H$ and keep the furnace $G$ at its operating temperature. The hydrogen escapes into the air at stopcock $H$.

When it is necessary to allow furnace $G$ to stand with no stream of hydrogen flowing, stopcocks $F$ and $H$ should be closed when the temperature of the furnace is as low as possible and with the hydrogen pressure as high as possible. A new determination must then be begun by sweeping hydrogen through the cold furnace $D$ and the train up to stopcock $F$, where the gas escapes into the air. Only after furnace $D$ has been heated at its operating temperature for several minutes is the hydrogen stream turned into the sample furnace $G$.

$111999^{\circ}-28-2$ 
While the train is being swept out, the three absorption tubes, $I, J$, and $Q$, are filled, their surfaces cleaned with ether, and then weighed. While waiting for the tubes, hanging in or near the balance case, to come to constant weight the potassium iodide solution in $N$ is changed. This renewal of the potassium iodide solution is necessary before each run in order that the concentration of free iodine in the solution shall be kept as low as possible. The ground-glass stopper of bottle $N$ is lubricated with moist phosphorus pentoxide. A solid cake of moist phosphorus pentoxide put on the finger and rubbed over the ground-glass surface served better than phosphorus pentoxide moistened to a sirupy consistency. The stopcock $L$, both stopcocks of tube $O$, and the stopcock of tube $P$ next to $O$ are all lubricated with moist phosphorus pentoxide. Ordinary stopcock grease is not permissible in these locations because of reactions with iodine vapors, causing the formation of products which are taken up in tube $Q$ and will be mistaken for carbon dioxide resulting from carbon monoxide derived from the sample. Stopcocks thus lubricated with rather viscous phosphorus pentoxide paste are best lifted very slightly from their seats when they are turned. If they are pressed into their seats on turning, the lubricated joint often is not tight.

The ground-glass connections of tube $Q$ and that of tube $J$ next to $K$ are not lubricated. These connections must be very carefully ground and may be held firmly pressed together by rubber bands. The use of a grease lubricant at these points must be avoided because of the reaction with iodine vapors mentioned above. The use of the phosphorus pentoxide lubricant was not convenient on the type of tube connections employed because of its accumulation in the open end of the train during the repeated inserting and removal of the tubes. All other stopcocks and ground-glass connections are lubricated with a medium hard stopcock grease made of vaseline, crude rubber, and paraffin.

When the absorption tubes have been weighed and the sample and antimony-tin alloy weighed out, the cap of the sample furnace tube is removed at the de Khotinsky seal (the cap next to stopcock $H$ ) while the flow of hydrogen through the furnace is increased 25 to 50 per cent over the normal rate of about 80 bubbles per minute at $C$ (approximately 1.85 liters per hour).

The boat containing the antimony-tin-iron alloy from the previous run, is then removed from the furnace tubes by means of a hooked-end wire and metal tweezers. The fused sample is then removed from the boat and the latter carefully and thoroughly brushed with a stiff bristle brush to remove as much of the fine graphite powder as possible. If the boat is not brushed quite free of graphite each time, an abnormally large amount of carbon monoxide will be indicated by the gain in weight in the third absorption tube in the next succeeding 
run. This is caused by an increase in the "hydrocarbon blank." (See IV, 4, (d).)

The cleaned boat containing the new sample and antimony-tin alloy is put back at the middle of the furnace tube. The cap is then resealed to the furnace tube and the weighed absorption tube $I$ put in place while the hydrogen is still flowing and with the stopcocks of tube $I$ open. Then by closing the stopcock at the exit end of tube $I$ the train is tested for tightness up to this point. Tube $J$ is then put in place and the ungreased ground-glass joint at the exit end of tube $J$ is wound tightly with a thin rubber strip (such as a strip cut from a toy balloon). The train as far as the outlet stopcock of tube $P$ is now tested for leaks by determining if it will hold a pressure of hydrogen equivalent to about $40 \mathrm{~mm}$ of mercury in manometer $B$. If the train is free from leaks, the stopcock at the outlet of tube $P$ is opened and the hydrogen is passed through the train at the regular rate (1.85 liters per hour). The gas burner for heating the oil bath, which surrounds tube $K$, is now lighted. After the gas has passed thus for one-half hour and the oil bath has reached $150^{\circ} \mathrm{C}$. the third weighed absorption tube $Q$ is placed in the train and the current is turned on in the sample furnace $G$.

In all the runs the sample furnace was brought from room temperature to $1,200^{\circ} \mathrm{C}$. in approximately two hours. The duration of the run is taken as the time the sample was held at the full temperature of $1,200^{\circ} \mathrm{C}$. after the two-hour period required to first reach that temperature. The minimum length of run required for complete recovery of the oxygen determined by this method in any particular class of material was estimated by making runs of increasing lengths of time on similar samples.

In Table 4 are given the results of seven analyses on milled samples of pig iron 4-c-2 in which the duration of the heating at $1,200^{\circ} \mathrm{C}$. was varied from 0 to 3 hours. Runs 21, 29, and 47 were made by heating the sample up to $1,200^{\circ} \mathrm{C}$., stopping the run as soon as the sample and furnace had just reached that temperature; that is, approximately two hours after the start of the heating from room temperature.

TABLE 4.-Recovery of oxygen as influenced by duration of heating of sample at $1,200^{\circ} \mathrm{C}$.

\begin{tabular}{|c|c|c|}
\hline Run No. & $\begin{array}{c}\text { Duration } \\
\text { of heating } \\
\text { at } 1,200^{\circ} \mathrm{C} \text {. }\end{array}$ & $\begin{array}{l}\text { Oxygen } \\
\text { found }\end{array}$ \\
\hline $\begin{array}{l}21 \\
29 \\
47 \\
63 \\
55 \\
57 \\
61\end{array}$ & $\begin{array}{c}\text { Hours } \\
0 \\
0 \\
0 \\
1 \\
2 \\
2 \\
3\end{array}$ & $\begin{array}{c}\text { Per cent } \\
0.022 \\
.028 \\
.028 \\
.058 \\
.12 \\
.11 \\
.10\end{array}$ \\
\hline
\end{tabular}


The values for oxygen shown in Table 4 indicate that not less than two hours heating of the sample at $1,200^{\circ} \mathrm{C}$. is necessary for the recovery of all the oxygen determinable by this method. Accordingly, all determinations were made with at least a two-hour heating period, and when working with lump samples the heating period was increased to two and one-half hours.

After a run is completed and the absorption tubes $I, J$, and $Q$ are removed, air purified by passing through phosphorus pentoxide and ascarite is passed through each absorption tube for one minute. (at a rate of about 3 liters per hour) in order to replace the hydrogen. Tube $J$ should be swept free of hydrogen by passing the air through it in the direction opposite to that of the flow of hydrogen through the tube as placed in the train on account of the danger of traces of moisture having condensed in the arm of the tube next to tube $I$ if, as was the case in the train employed, it is necessary to unseal with a handtorch flame the de Khotinsky cement joint between $I$ and $J$. All three tubes are again carefully cleaned with ether and weighed.

\section{BLANKS}

It was soon evident that in the hydrogen antimony-tin method of determining oxygen in cast irons there were many sources of oxygen or of other gases which might be absorbed in the weighed tubes and mistaken for oxygen. These sources may be enumerated as follows:

(a) The oxygen from the sample; the value it is desired to obtain.

(b) Oxygen from air or moisture adsorbed on the alundum boat during the loading of the sample and any oxygen from the reduction of oxides of which the boat is made.

(c) Oxygen from oxides in and air adsorbed on the crushed antimony-tin alloy.

(d) Hydrocarbons formed from the action of hydrogen on carbides or free graphite. Such hydrocarbons apparently react to some extent with the iodine pentoxide yielding oxidation products which are recovered in the weighed tubes but which do not represent oxygen derived from the metal sample.

(e) A possible small but continued reduction of the oxides of the alundum boat even after adsorbed air has been removed.

(f) A possible small but continued reduction of oxygen in the antimony-tin alloy after adsorbed air and surface oxidation of the crushed alloy has been removed.

It thus became necessary to make four distinct kinds of runs for each sample of different composition or of different form-that is, millings or lump sample - or of different weight or ratio of sample to alloy. These four types of runs are designated as-

1. Beginning sample run (BSR).

2. End sample run (ESR). 
3. Beginning blank run (BBR).

4. End blank run (EBR).

A "BSR" value is obtained according to the regular procedure as described for a typical determination, opening the sample furnace and placing a new sample and portion of alloy in a boat previously used for several runs. Such a run, therefore, includes the oxygen from the sources designated above as $a, b, c$, and $d$.

An "ESR" value is obtained by the regular heating period on a boat, sample, and alloy remaining from a "BSR" determination without, however, opening the sample furnace tube between the two runs. This run then includes the oxygen from sources designated above as $d, e$, and $f$.

The "BBR" value is obtained by making a regular run opening of the furnace tube but putting the proper weight of antimony-tin alloy only in the boat, omitting the sample. Such a run gives the combined values of oxygen from $b$ and $c$.

The "EBR" value is obtained by a run after the "BBR" determination without opening the sample tube. This gives the combined values for oxygen from $e$ and $f$.

Then, since

$$
\begin{aligned}
\mathrm{BSR} & =a+b+c+d \\
\mathrm{ESR} & =d+e+f \\
\mathrm{BBR} & =b+c \\
\mathrm{EBR} & =e+f
\end{aligned}
$$

$\mathrm{BSR}+\mathrm{EBR}-\mathrm{BBR}-\mathrm{ESR}=(a+b+c+d)+(e+f)-(b+c)-(d+e+f)$

$=a$, the oxygen content of the sample only.

Many preliminary blank runs were made to develop the technique of the method and to indicate the complexity of the blank. It was in the course of this preliminary work that it became evident that wash bottle $N$ and drying tubes $O$ and $P$ were needed between the iodine pentoxide tube and the third absorption tube in order to prevent iodine from passing into the absorption tube; that all traces of oxygen must be kept from entering the sample tube of furnace $G$ at any time, even after the tube had cooled to room temperature, probably on account of the ready oxidation of antimony deposited from the vapor in the cooler portions of the tube. Such entrance of oxygen was guarded against by keeping the tube at all times full of hydrogen which had passed over hot copper chips and through phosphorus pentoxide. As a further precaution, the unsealing of the cap for opening the sample tube as well as the resealing after replacing the boat or boat and sample was carried out with a flow of pure hydrogen through the sample tube, made at a sufficiently increased rate, so that the escaping hydrogen, when ignited by the flame of the torch used for softening the cement, should not burn back in the end of the 
sample tube. The early blank runs also showed the need for precise control of the temperature and of the duration of the runs. The need of conditioning a new alundum boat by repeated heatings in hydrogen at $1,200^{\circ} \mathrm{C}$. or higher was also clearly demonstrated.

\section{APPLICATION OF METHOD TO CAST-IRON SAMPLES}

The results of the analyses of both milled and lump samples of pig iron No. 4 by the hydrogen-antimony-tin method are given in Table 5. The analyses on milled samples show, in the first place, that a heating period of two to three hours is required for complete reduction, as has already been pointed out in a briefer summary of these same analyses in Table 4. The analyses made with two and three hour heating periods gave for the oxygen content of the milled samples 0.10 to 0.12 per cent. These results are to be compared with the analyses listed in Table 3 where the average oxygen content of this same milled sample was found by the vacuum-fusion method to be 0.07 per cent. This latter value is to be regarded as including: somewhat less than the total of the adsorbed air and moisture, since in the vacuum-fusion method the preliminary evacuation of the furnace tube containing the cold sample may well be expected to remove a portion of the less firmly held adsorbed air and water. This preliminary evacuation is carried out through a by-pass, and extracted oxygen or moisture is thus lost. On the other hand, in the hydrogen-antimony-tin method there is no preliminary evacuation when the sample is placed in the cold furnace. The stream of dry hydrogen immediately sweeps over the sample and into the first weighed absorption tube, where any more loosely adsorbed water will be recovered and so must appear as a part of the final result. Some of the adsorbed oxygen which is lost in the preliminary evacuation of the vacuum-fusion method may also be retained by the sample in the hydrogen-reduction method until the heating of the sample has progressed enough to bring about the reduction of the oxygen to water vapor.

In the case of the analysis of milled samples of the pig iron, therefore, the hydrogen-antimony-tin method, when carried out with due regard to the length of the heating period at $1,200^{\circ} \mathrm{C}$., to the complexity of the blank correction, and with the technique as described, gave results for oxygen which were of the same order as those obtained by the vacuum-fusion method on the same milled sample. As was shown, however, in the preliminary analyses by vacuum fusion, the oxygen values obtained from milled samples are greatly in error, due to adsorbed moisture and air. The hydrogen-antimony-tin method must, therefore, be applicable to lump samples if it is to give the true values for the oxygen content of a cast iron. 
The results of analyses made by the hydrogen-antimony-tin method on solid samples of pig iron 4-b-2 are given as runs $65,67,69$, and 71 in Table 5. These four analyses gave values of $0.020,0.013$, 0.025 , and 0.011 , an average value of 0.017 per cent oxygen, to be compared with the average of 0.012 per cent oxygen obtained by the vacuum-fusion method on lump samples of $4-b-3$ or with the average of 0.011 per cent oxygen, the average of lump samples of $4-\mathrm{c}-3$.

Finally, an analysis was made on a sample of a cast iron of high manganese and silicon contents (designated as iron "E") of the following composition:

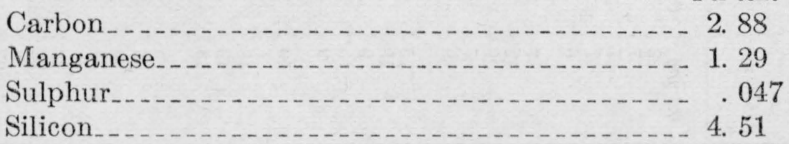

This iron showed an oxygen content of 0.043 per cent by the hydrogen-antimony-tin method using a lump sample. (Run 77, Table 5.) Three determinations by the vacuum-fusion method gave values of $0.038,0.035$, and 0.041 per cent oxygen for this same sample, or an average of 0.038 per cent.

The hydrogen-reduction method thus gave results for oxygen slightly higher than the vacuum-fusion method when using lump samples of both pig iron No. 4 and cast iron "E." 
$\mathrm{T}_{\mathrm{ABLE}}$ 5.-Oxygen in cast irons as determined by the antimony-tin-hydrogen method

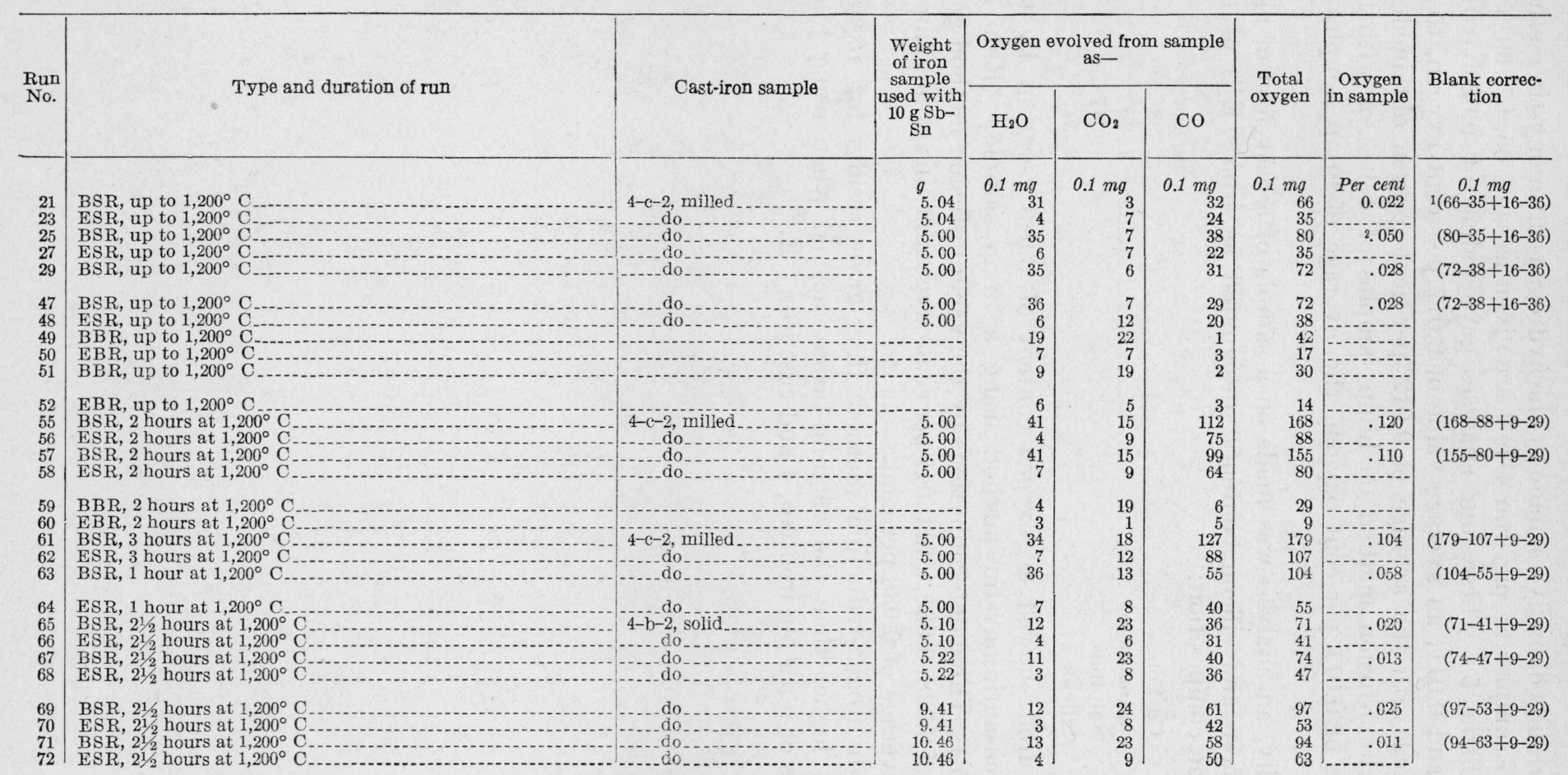


77 BSR, 21/2 hours at $1,200^{\circ} \mathrm{C}$

"E," soli

$\mathrm{BBR}, 21 / 2$ hours at $1,200^{\circ} \mathrm{C}$
$\mathrm{EBR}, 21 / 2$

-

1. The figures in this column indicate the values (in $0.1 \mathrm{mg}$ ) used for the blank correction in the calculation. The figures in the parentheses in all cases are the expression "BSR$\mathrm{ESR}+\mathrm{EBR}-\mathrm{BBR}$ " Which has already been shown to give the corrected value for oxygen in the sample. The values for EBR and BBR un in $1,200^{\circ} \mathrm{O}$., since the difference between $\mathrm{EBR}$ and $\mathrm{BBR}$ is what is actually used in the calculation, and this difference was found to be the same for a given sample (pig iron $4-\mathrm{c}-2$ ) for runs up to $1,200^{\circ} \mathrm{C}$. and runs held for 2 hours at $1,200^{\circ} \mathrm{C}$.

The result of this run, higher than the duplicate runs 21,29 , and 47 , is probably in error, due to the fact that the alundum boat used in this run was not carefully brushed free of graphite powder remaining rom the previous runs but was only roughly scraped with an iron rod. The value for $\mathrm{CO}$ in the third weighed tube is thus quite probably too high on account of an abnormally high "hydrocarbon blank." 


\section{SUMMARY}

A summary of the results obtained for oxygen by the two methods of analysis on both milled and lump samples of pig iron No. 4 and on lump samples only of cast iron " $\mathrm{E}$ " is given in Table 6. From this it is seen that both methods gave the same result on millings of pig iron No. 4, but that vacuum-fusion analyses of lump samples of this same pig iron proved that the determinations made by either method on milled samples were greatly in error, due chiefly to adsorbed moisture and air on the pig-iron millings. The analyses on lump samples of this same iron by the hydrogen-reduction method. gave an oxygen content slightly higher, by approximately 0.005 per cent, than that indicated by the vacuum-fusion method. In the same way the hydrogen-reduction value for oxygen in cast iron " $\mathrm{E}$ " was higher than the vacuum-fusion result, again by 0.005 per cent.

TABLE 6.-Summary comparison of results for oxygen in cast irons

\begin{tabular}{|c|c|c|c|}
\hline Sample No. & Form of sample & $\begin{array}{l}\text { Reduction by hydrogen at } 1,200^{\circ} \mathrm{C} \text {. } \\
\text { with addition of antimony-tin }\end{array}$ & $\begin{array}{l}\text { Vacuum fusion at } \\
1,475^{\circ} \mathrm{C} \text {. in graphite }\end{array}$ \\
\hline $\begin{array}{l}4-\mathrm{c}(2 \text { or } 3) \\
4-\mathrm{b}(2 \text { or } 3) \\
4-\mathrm{c}(3) \\
\mathrm{E}\end{array}$ & $\begin{array}{l}\text { Millings.- } \\
\text { Lumps.-- } \\
- \text { do }_{-.--}\end{array}$ & $\begin{array}{l}\text { Per cent oxygen } \\
0.11 \text { (average of } 3 \text { ) } \\
0.017 \text { (average of } 4 \text { ) }\end{array}$ & $\begin{array}{l}\text { Per cent oxygen } \\
0.07 \text { (average of } 7 \text { ). } \\
0.012 \text { (average of } 2 \text { ). } \\
0.011 \text { (average of } 4 \text { ). } \\
0.038 \text { (average of } 3 \text { ). }\end{array}$ \\
\hline
\end{tabular}

The precision of the vacuum-fusion method, as indicated by the average deviation from the mean of either the blanks for oxygen listed in Table 1 or the last six blanks in Table 2 is $0.0003 \mathrm{~g}$ oxygen, or 0.001 per cent oxygen when using a $30 \mathrm{~g}$ sample. A similar calculation, based on the average deviation from the mean of the corrected values for oxygen for the first four vacuum-fusion analyses of Table 2 (samples in which segregation of oxygen in the pig iron does not enter), also indicates a precision of 0.001 per cent oxygen.

If the precision of the hydrogen-reduction method is calculated as based on the deviation from the mean in blanks, it will be found that the average deviation from the mean of the net blanks of runs 65 and 67 (Table 5) is $0.0003 \mathrm{~g}$ oxygen, equivalent to a precision of 0.006 per cent on a $5 \mathrm{~g}$ sample; and that the average deviation in the case of runs 69 and 71 is $0.005 \mathrm{~g}$ oxygen, equivalent to 0.005 per cent on a $10 \mathrm{~g}$ sample. The precision calculated from the three determinations on milled samples (runs 55, 57, and 61, Table 5) is also 0.006 per cent oxygen. An increase in the size of sample used is of less value in increasing the precision than might be expected, possibly due to the fact that the oxygen equivalent of the "BSR" and "ESR" runs, as well as the value of the net blank, will increase with increase in weight of sample due probably to the increase in the 
"hydrocarbon" blank caused by the greater amounts of carbides and free graphite for reaction with hydrogen.

Within the precision of the hydrogen-reduction method, therefore, the agreement obtained between values on solid samples in runs 65 , 67,69 , and 71 is all that could be expected. The maximum range in these four determinations is 0.014 per cent. The average deviation from the mean is 0.005 per cent oxygen. The maximum difference in results obtained by the hydrogen-reduction method in check determinations on the milled samples was 0.016 per cent. With the oxygen content of the milled samples at a little over 0.10 per cent this range was not high enough to make the agreement with vacuumfusion values unsatisfactory. In the case of solid samples, however, containing approximately 0.012 per cent oxygen this same range in hydrogen reduction values is more noticeable and serious.

A point of interest attaches to the results of this work in comparison with the results reported by Thanheiser and Müller ${ }^{12}$ as to the influence of silicon on the determination of oxygen by reduction in hydrogen. These investigators found that only a small part of the oxygen in low-carbon iron alloys was obtained by the hydrogenreduction method (alloying the sample with antimony only) when silicon was present in amounts of 0.1 per cent or more. The results of the analyses made in the present investigation indicated that the recovery of oxygen from a pig iron containing 1.31 per cent silicon and 3.68 per cent carbon was, at least, as complete as by the vacuumfusion method. It is to be inferred, then, either that the presence of considerable amounts of carbon in the samples used in the present investigation have prevented the retention of the oxygen by the silicon in the sample, as experienced by Thanheiser and Müller, or that the vacuum-fusion method may fall short of complete determination of the oxygen in a high-carbon, high-silicon alloy to the same degree as the hydrogen-reduction method. The first explanation is more probably the correct one as is indicated by the results obtained by Oberhoffer, Piwowarsky, Pfeifer-Schiessl, and Stein ${ }^{13}$ on the distribution of oxygen among the gases $\mathrm{H}_{2} \mathrm{O}, \mathrm{CO}$, and $\mathrm{CO}_{2}$ evolved from ferrous alloys of various carbon content when subject to hydrogen reduction analyses. They found that from steels of carbon content ranging between about 0.1 and 1.0 per cent from 40 to 70 per cent of the oxygen was evolved as water vapor and only 25 to 30 per cent as carbon monoxide. When, however, the sample for analysis was a gray iron containing 3.26 per cent carbon, some 80 per cent of the evolved oxygen was combined as carbon monoxide and only 12 per cent as water vapor. The reduction of oxides in the sample by carbon appears to play so large a part in the case of 
the cast irons used in the present investigation as to make nonapplicable the limitation of the hydrogen-reduction method which was found by Thanheiser and Müller to apply in the case of lowcarbon steels containing silicon.

\section{CONCLUSIONS}

A comparison of the vacuum-fusion and the hydrogen-antimonytin reduction methods for the determination of oxygen in cast irons resulted in the following observations:

1. The sample used in the hydrogen-reduction method must be a solid sample, in the form of one or two lumps, rather than millings, since samples of the latter form may adsorb air and moisture equivalent to oxygen of four to eight times the real oxygen content of the iron as shown by vacuum fusion analysis.

2. The precision of the hydrogen-reduction method was indicated as 0.006 per cent oxygen using a $5 \mathrm{~g}$ sample, and 0.005 per cent using a $10 \mathrm{~g}$ sample. This precision is increased but little by using larger samples, since certain factors in the "blank" appear to change with size of sample, and the net value of the blank increases with increasing size of sample. The precision of the vacuum-fusion method was indjcated as 0.001 per cent using a $30 \mathrm{~g}$ sample.

3. The rather complicated nature of the "blank" for the hydrogenreduction method was pointed out. This blank required for its proper evaluation no less than four slightly differing types of runs.

4. Within the precision of the method the hydrogen-antimony-tin analysis gave the same values for oxygen as the vacuum-fusion method on samples of two different cast irons whether using millings or lump samples. The precision of the hydrogen-reduction method was, however, of the same order of magnitude as the oxygen content of one of the cast irons used, namely, about 0.01 per cent and about 25 per cent of the oxygen content of the second cast iron employed. The precision of the fusion method, on the other hand, was from about 2.5 to 10 per cent of the oxygen content of the cast-iron samples. The fusion method, therefore, was more satisfactory than the hydrogen-reduction method.

5. The limitation of the hydrogen-reduction method to siliconfree samples, which has been shown to be necessary in the case of low-carbon iron alloys, does not appear to hold for high-carbon iron alloys of the type used in this investigation.

Washington, May 29, 1928. 